\title{
Exploring Science Identity Development of Women in Physics and Physical Sciences in Higher Education
}

\section{A Case Study from Ireland}

\author{
Ebru Eren ${ }^{1}$ D \\ Accepted: 25 March 2021 / Published online: 6 May 2021 \\ (C) The Author(s) 2021
}

\begin{abstract}
This study investigates women's science identity development in physics and the physical sciences in higher education through a gender perspective. It arises from the real-life sociological issue of women's lower level of participation in physics and physical sciences in Ireland, where the gender gap is the highest of all science disciplines, according to the Higher Education Authority (HEA) reports of recent years. Twenty-nine undergraduate, graduate students, and postdoctoral researchers from four Dublin universities were interviewed to achieve an in-depth understanding of gender and science issues from their standpoints. The focus was on how they constitute their identities as a 'scientist' in relation to their gender. The result of this study illustrates a variety of possible science identity constitutions of women both from an individual and collective identity perspective. Understanding women's science identity development help brings a general view about developing a more welcoming and flexible science culture for individuals who think they do not fit well or who are left outside of the certain prevailing norms in the scientific climate. It also can allow seeking a way of challenging and changing the predominant culture and the prevailing masculine norms in doing science.
\end{abstract}

\section{Introduction}

In Ireland where this study took place, figures published by the HEA (2017/18) highlight gender inequality as an issue in the fields of physical sciences, especially in physics, mathematics, and physical sciences (not further defined) fields. ${ }^{1}$ According to HEA reports (2016; 2017/18) in the field of physics and physical sciences at each stage of the scientific career ladder, more men than women enrol, and more women than men leave the academic science at the highest level. It shows that women are still under-represented in Ireland

1 Physics and physical sciences have been introduced as separate categories based on the HEA reports of Ireland.

Ebru Eren

erene@tcd.ie

1 School of Education, Trinity College, Dublin, Ireland 
today within these academic disciplines. This motivates in-depth investigations of issues of science, gender, and identity within these domains.

In this study, I examined female students' and early career researchers' ${ }^{2}$ self-identification with science focusing specifically on their gender identity along with other overlapping identities in a small national sample of four public research universities in Dublin, Ireland. Using an identity-based analytic lens allowed me to focus on my participants' perspectives on their views of themselves. I particularly focused on the conflict between the stereotypes associated with a women's role in society, and a woman's perception of herself as a scientist. To deeply explore gender issue in the field of physics and physical sciences, the following research question was posed:

1. How do female students and early career researchers in physics and physical sciences fields in higher education construct their science identity related to their gender identity?

I explored the construction of a science identity through women's narratives about what it means to be a 'scientist' and how they view themselves as 'scientists'. ${ }^{3}$ The process of this construction may be complex and sometimes contradictory. I particularly looked at how they view their gender and science identities as well as how these two identities affect each other. This study focused on science identity development of women at undergraduate, graduate, and postdoctoral level. This way, women's science identity construction could be observed at various academic levels.

I refer to two different identity categories - woman and scientist—each of which has its unique political, cultural, social, and economic practices and representations, and each of which has its own attachment to the individuals through social norms. For a broader understanding of science and gender relations and their effect on science identity development, what makes a 'woman' and a 'scientist' need to be better discussed. According to the social construction of gender, 'woman' as a gender category is made and practiced by individuals in their everyday lives through interaction, speech, and bodily acts and activities. Similarly, individuals learn how to be a scientist and how to attach to its norms and culture.

My focus was on the power of language that the participants used to describe 'what woman means', and 'what scientist means to them' as well as 'how they do science' and 'how they do gender'. Just like 'gender is an act which is rehearsed, actualized and reproduced' (Butler, 1988), being a scientist is based on repeated performances that involve the socialization of individuals into the norms and discourse practices of science (Brown, 2004). The performative conceptualization of 'gender' and 'science' identity allows for a more fluid understanding of them, and for a transformation of the prescriptive stereotypes that come with these identities.

Women's science identity is viewed as a 'becoming' process that has a strong connection with the past and present. The next section aimed to show the readers beneath the surface of what is being discussed today in terms of women's collective science identity construction, their 'agency', and positioning in science before investigating women's science identity development today through lived experiences of the participants of this study.

\footnotetext{
${ }^{2}$ Early career researchers refer to doctoral students $(\mathrm{PhD})$ and postdoctoral researchers.

3 In this study, the word 'scientist' refers to a 'science person' within the participants' disciplinary domain. It could be a physicist, chemical scientist, physical scientist, energy scientist, astrophysicist, medical physicist, earth scientist, in brief, a person who does science within their particular academic disciplines.
} 


\section{Literature Review}

\subsection{Women as 'Agents/Knowers' of Science}

Feminist historians of science and women scientists have made significant contributions to the visibility and recognition of women in this field in terms of challenging the gender stereotypes, questioning the androcentric (male-centred) practices in science, making visible, and celebrating women's achievements in science (Schiebinger, 1993, 2000; Spongberg et al., 2005). Especially after a late twentieth century when feminist philosophy emerged as a distinctive field. Feminist theorists began to ask 'why, and how, have women all over the world been epistemologically dis-authorized as knowers' (Alcoff \& Kittay, 2007, p. 11).

While rational knowledge has long been based on the lives of men in the public sphere, 'the feminine has been associated with what rational knowledge transcends, dominates or simply leaves behind' (Lloyd, 1996, p. 41). Therefore, it is not surprising that Marie Curie was rejected for membership in the Academie des Sciences in France in 1911 when she won her second Nobel Prize. Similarly, even though The Royal Society, the world's oldest independent scientific academy, was founded in 1660, women were not permitted to become fellows of the Royal Society until 1945. Even worse, it was just a few years ago when Nobel Prize scientist Tim Hunt (2015) said that female scientists cause trouble for men in labs.

This mind-set which has given privileges to men for producing and controlling the knowledge has resulted in gendered knowledge and a gendered division of social roles that have led to the marginalization of women in 'male-dominated' areas which of them is science. Not only have women been excluded from male-dominated areas but others (from a white male norm), as argued by Code (2007), both female and male, have been judged variously incapable of the reasoning from which alone valid knowledge is derived from.

Reason and rationality are regarded as prerequisites for science and scientific knowledge. In western philosophy which has a hierarchical division between rational and irrational, 'only people who can claim or-are accorded-a place within the rational can expect the acknowledgment and respect and the entitlement to social-political epistemic authority' (Code, 2007, p. 212). Especially after the Enlightenment, the man of reason has been the man of science. It is so deeply embedded in our minds that I could not agree more what Code (2014) says in her article that the subject S, in the standard S-knows that- $p$ formula in which propositional knowledge claims are ordinarily stated, is presumptively male to the extent that there is no need even to mention his maleness. In this circumstance, if this ' $\mathrm{S}$ ' is Sam, let us say, Sam knows that the tree is green, then the sex of the knower, as stated by Code (2014) would be regarded as 'being of no greater significance than the size of his feet' (p. 10). But the sex of the knower is epistemologically significant if it is not within the norms. So, if this ' $S$ ' as someone not male, not white, not western, not any other stereotypical individual, his/her identity as a knower would matter. Because, 'standard-setting knowledge in western societies mostly derives from the experiences of white, middle/ upper-class educated men' (Code, 2014, p. 11).

\subsection{Feminist Reflections on Science}

A feminine perspective of science, according to Keller (1985, p. 8) confronts us with the task of examining the roots, dynamics, and consequences of this interacting network of 
associations and disjunctions - together constituting what might be called the 'science and gender system'. As a woman scientist, a mathematical biophysics specialist, Keller has tried to determine how the gender has affected the making of science. Especially since the early 1980s, feminist epistemologists and philosophers of science have been engaged in debates about the philosophical conception of epistemic agency, justification, reason, objectivity, and scientific knowledge. They have adopted different approaches to women's questions in science and knowledge. Feminist empiricists assert that 'empiricism committed to objective evidence-gathering and justification, informed by feminist ideology could produce more adequate knowledge than classical empiricism' (Code, 2014, p. 11). As feminism has a political agenda, feminist empiricism has undoubtedly feminist values at the core of its theory. So, it rejects the view that science is value-free. According to the feminist standpoint theory, knowledge is a socially situated and human activity just like science is. Since they are outsiders within, marginalised groups can be more aware of things more than non-marginalised ones, so they can reach more objective results.

From a feminist poststructuralist view, knowledge which was defined as justified true belief came to be understood as 'power' (Keller, 1987), as 'the power to dominate nature with the rise of modern science' (p. 11). In the case of science, Keller further claimed (1987) that the construction of gender as the construction of exclusion of women, of the feminine, of simultaneously of the alternative meanings of power that knowledge might engender. From this perspective, the most central issue is gender, science, and power. For Keller (1987), to ask women, scientists, to accept the notion of a different science (feminine science) would be to ask them to give up their identity as scientists in the same way the traditional science has asked them to give up their identity as women. So, neither homogenous nor divided, but a wider representative, richer and multi-dimensional landscape is a prerequisite for knowledge in science. Working from a feminist poststructuralist perspective, I claim that an individual can be comprised of several 'possible selves located in different story-lines' (Sowell, 2004, p. 44). Thus, women's science identity, which is the focus of this study, is conceptualised 'flexible', 'becoming', and 'constantly unfinished entity'. As stated before, both feminist empiricism and feminist standpoint theory require a stable 'woman' subject. However, in this study, what 'woman' means shifts over time and place and is contextual and situational.

\subsection{Masculine Culture of Physics and Physical Sciences and Women's Challenges Within These Fields}

Gender differences across science fields suggested that existing gender inequality in science is somewhat field-specific (Cheryan et al., 2016; Francis et al., 2017; Gisler et al., 2018; Kalender et al., 2019). For example, heavily male-dominated fields such as physics and certain subfields of physical sciences are viewed as more strongly associated with masculine stereotypes compared to relatively more gender-balanced fields such as life sciences and chemistry (Smyth \& Nosek, 2015; Turnbull et al., 2017). In line with these studies, in this research, the focus was given to the physics and physical sciences as they show the largest gender imbalanced of all science disciplines in Ireland (HEA 2017/2018).

The analysis employed by Smyth and Nosek (2015) showed that for both men and women in sciences, the weakest explicit stereotypes were in the domains where women are more strongly represented such as health and biological sciences, and the strongest was seen where women are least represented, such as physical sciences. Similarly, in 
a recent study by Turnbull et al. (2017), the results showed gender differences in subject enrolment consistent with gender stereotypes. Their analysis found out that after taking a first-year physics course, female students were around 2.5 times more likely to study life science subjects (medicine and biology) in later years compared to male counterparts. Turnbull et al. stated that (2017) gender differences in science subjects may not be present in early childhood but emerge by the end of high school, and at the university level, the disparity may even widen further. This argument is supported by influencing factors contributing to the gender gap at a more advanced level of science.

In research focusing on young people to analyse the discursive assumptions made in relation to gender and physics, it was identified three key factors: equality of opportunity continued gender discrimination in and around physics, and construction of physics as a hard and masculine subject (Francis et al., 2017). In another study (Gisler et al., 2018), it was found out that perceived lack of fit, schooling differences, lower self-efficacy, and lack of female role models may represent some of the biggest impediments for attracting women into highly male-dominated STEM fields. It was further stated that (Gisler et al., 2018) the wider gender disparity at higher level scientific occupations may stem from unfair workplace practices, a lack of family-friendly policies, and/or workplace cultures and institution-level factors.

An individual's disposition towards certain subfields of science may also be influenced by environmental context. Murphy et al. (2007) found that women were affected by the numerical representation of women in conferences. They tended to have a higher level of belonging after they witnessed a gender-balanced conference setting. Murphy et al. (2007) concluded that women felt more identity-safe among other women.

Francis et al. (2017) draw attention to the importance of representation of women in physical science saying that the symbolic hegemony that physical sciences are 'hard' and 'masculine' domain should be disrupted in order to increase the representation of women in the sector. Their findings (2017) suggested that the lack of women in physics, both in reality and as presented in popular media, perpetuate the construction of physics as an inhospitable domain for women. In another research (Gonsalves et al., 2016) which focused on masculinities produced related to physics, it was claimed that masculinities are not only relevant to men but also in relation to women's experiences in physics. In this study, masculinity was viewed as performative rather than something inherent to men. What I have understood from Gonsalves et al. research is that women also perform masculinity rather than passively perceive the culture of physics as masculine. The construction of masculinity, in Gonsalves et al.'s analysis, involves performing, practicing, and expressing different masculinities through the practice of physics in a different context (e.g. physics classrooms, lab) and taking up physical skills (e.g. technical competence, analytical skills, hands-on skills, strength, and physical efforts).

From the studies above, it can be concluded that the difference of female representation across science disciplines can be associated with the strength of gender stereotypes and/or the heavily male-dominated and masculine nature of certain scientific fields.

\subsection{Gender Stereotypes and Bias in Science}

A stereotype is defined as a fixed, often simplistic generalization about a particular group or class of people (Cardwell, 2014, p. 227). Of particular relevance to this 
research is the stereotype that men are better at mathematics and science than women (Good et al., 2008; Spencer et al., 1999). Physics and physical science which are the focus of this research requires science and mathematics competence. These fields are still overly male-dominated and masculine where 'women are under-represented compared to life science subjects' (Turnbull et al., 2017). There are successful stories of women and other minority groups in science. However, 'men do science' is still a widespread stereotype. Lederman and Bartsch (2001) have claimed that the normal image of scientists has been and continues to be, 'white, middle/upper class, solitary, laboratoryoriented man, and it is necessary to modify 'scientist' when we try to include other types of people' (p. 9).

Lane et al. (2012) have reported that 'people with strong ties to their gender seemed to be most affected by gender stereotypes' (p. 223). Butler (2015) claims that there are ways to minimise the importance of gender in life or to confuse gender categories so that they no longer have descriptive power on us. I agree with Butler on her view that strongly identifying ourselves in a particular way might lead to a descriptive power on us which also reinforces the stereotypes associated with that identity. Gender/sex stereotypes can be eliminated by removing gender labels in our minds, and by seeing a gender identity not as destiny, or maybe, as Fryer and Wilchins (2012) puts, 'by thinking queerly about our sex, our gender, our race, our ethnicity, and our very selves' (pp. 11-12). It is not only to transcend our normative thinking but also to challenge the very terrain upon which thinking occurs. As suggested by Fryer and Wilchins (2012), normative thinking is a kind of thinking 'whereby we accept the world as given to us- whereby we do not question the assumptions that underlie our everyday goings-on, nor do we see our role in the world as critical thinkers' (p. 5). For Fryer and Wilchins (2012), this way (thinking queerly) we can break the assumptions that 'all professionals are white, that all presidents will be men, or that all people are straight' (p. 5).

As argued by Nosek and Banaji (2002), the strength of female gender identity was associated with increased negativity and weaker identification with math. This study revealed that women and men held equally strong implicit stereotypes linking math to males. Steele (1997) has argued that 'for members of a negatively stereotyped group who are identified with domains in which these stereotypes apply, the threat of these stereotypes can be sharply felt and, in several ways, hampers their achievement' (p. 614). Steele (1997) defines this feeling of failure as a stereotype threat which is a situational a 'threat in the air' - that, in general form, can affect the members of any group about whom a negative stereotype exists (p. 614). So, in a certain group-dominated working environments, this group might justify their dominance by adopting certain stereotypes that treat this group as a normative and superior and denigrate other groups. Thus, increasing the number of underrepresented groups in science is important in terms of eliminating negative ideologies and stereotypes towards minority groups. Negative racial and gender stereotypes are likely consistently harmful to racial minorities and women alike.

Racial and gender ideologies might interact and impact people with overlapping identities, such as women of colour and queer people of colour. Also, a person's gender, racial, and ethnic identities may have an impact on his/her science identity. Carlone and Johnson (2007) demonstrated a connection between the experiences and making meanings of science, gender, and race identities of women. They (2007) have found out that women of colour can persist in science without either gaining or being denied recognition from meaningful scientific others, but still redefining their understanding of what it means to be in science and whose recognition is important to them. I understand from 
this finding that one's perception, understanding, and performance of his/her identity is flexible and can be redefined. Individuals, especially underrepresented groups, can reinterpret their identities in science and create new and a wide range of 'scientist subjectivities' (science identities) for themselves and for those who are often excluded from doing science.

\subsection{Science Identity Construction}

Identity formation is a complex process. Thus, studying identity is a challenging and daunting task for researchers. As Carlone suggested (2012), part of the problem lies in the difficulty of 'theorizing the concept in rigorous, cohesive, and empirically accessible ways' (p. 9). There has already been a rich literature which directly investigates science identity development of women, especially case studies through interviews. Most of these studies have adopted Carlone and Johnson's identity analysis model and further developed it (Espinosa, 2011; Hazari et al., 2013; Herrera et al., 2012).

One recent example of a case study of the relationship between science identity and sense of belonging conducted in Ireland could be a study of Mooney et al. (2018). They conducted mixed-method single case research to investigate the role that gender plays in deciding to study Computer Science at University College Dublin in Ireland. The study has revealed significantly lower levels of sense of belonging reported by female identity students providing a cause for concern considering the link of sense of belonging with progression in higher education and general well-being (Mooney et al., 2018). This study is informative in terms of determining whether there is a difference in the sense of belonging between the genders through the example of one Irish university.

Sense of belonging has been found to be one of the most important determinant of STEM identity development (Espinosa, 2011; Smith et al., 2013; Stout et al., 2013; Good et al., 2012; Trujillo \& Tanner, 2014). The researchers have found that women's sense of belonging impact their achievement in STEM and their subsequent intent to pursue in STEM domains. Results also have shown that community involvement and mentoring positively affect science identity (Good et al., 2012; Trujillo \& Tanner, 2014) while negative cultural stereotypes about one's group ability are associated with a lower sense of belonging (Stout et al., 2013). These findings have highlighted the importance of developing a sense of belonging for a strong science identity.

I would like to draw particular attention to a longitudinal single case study of a woman called Sara, who previously considered dropping out of high school, then developed a strong science and mathematics agency through her experiences in high school science and chose a chemical engineering major in college, but completely lost her interest and finally left the college (Godwin \& Potvin, 2017). This case has attracted my attention in the way that Sara first developed a critical science (STEM) identity and experienced a 'disconnect between her developed identity and empowerment over time' (Godwin \& Potvin, 2017, p. 446). The study of Sara showed me a strong connection between belonginess and STEM identity and how a STEM identity can change in one's early academic career life.

Science and gender identities of the women who participated in this study were explored as related to a sense of belonging to science and the factor of performance (doing science). The identity lens I used in this study was influenced by the identity theory of Gee (2000), performativity theory of Butler (1988), and the concept of sense of belonging. Within the research literature on sense of belonging, the focus is on a feeling of a belonging to a 
particular group, people, and activities (Mooney et al., 2018; Good et al., 2012; Stout et al., 2013; Freeman et al., 2007; Trujillo \& Tanner, 2014). Unlike the previous studies, in my study, there are two facets of the sense of belonging, one of which is related to the development of attachment to the scientific community (community attachment) and the other to the development of an interest in science (emotional attachment). The factor of interest was previously used in Hazari et al.'s (2010) study in which they have developed a framework for physics identity in high school. Hazari et al.'s (2010) interest dimension is treated as a separate variable. In this study, it is framed within the concept of sense of belonging as it refers to emotional attachment to science as individual level.

Gee's and Butler's theories shaped the performative dimension of the identity construction and formed the factor performance (doing science) in my science identity framework. Gee's identity theory puts emphasis on the interactive and interpretative aspect of identity construction, which in my case, involves doing science, making meaning out of it, and viewing yourself as a part of a scientific community. This approach also gives an active role to the person in terms of forming an identity. It also makes identities fluid and active. So, I argue that when women constitute their science identities, they also have the possibility to transform the norms, the values, and activities of science as well as the particular characteristic of a scientist. My identity framework also drew from Butler's performativity theory. In this study, identity is not considered as an ontological quality that corresponds to the essence of the individual. From a performative perspective, identity is viewed to open to a continual process of transformation in this research. From Butler's view, the character of identity is never fixed, but always in process.

\section{Theoretical Framework}

The empirical study integrated theories from feminism, intersectionality, and queer theory in order to gain a more holistic understanding in examining women's science identity development. The feminist lens applied in this study offers a critical perspective for understanding the gendered social order in the culture of science focusing particularly on women's individual experiences. Through the interviews with women, this study questioned the certain social and gender roles of women and stereotypes associated with those roles which may hinder their professional (science) identity, or which may conflict with their science identity.

In the context of this study, the emphasis was put on how women's gendered experiences and gender performances might influence their science identity development, but gender alone provides a limited understanding of how they construct their science identities, their struggles, conflicts, and more generally women's low engagement in physics and physical sciences. From an analytical perspective, the lens of intersectionality allowed me to develop an inclusive perspective in order to understand their life, experiences, and positionality within their scientific community.

I expanded my theoretical approach to include queer theory to challenge the normative social ordering of identities and subjectivities along a gender binary. In this study, gender identity is viewed as a social construction instead of a personal trait. Thus, I have conceptualised gender as a 'performance' and tried to examine how the participants performed their gender, how that performativity influenced their science identity development and sense of belonging to science. In this study, heavily influenced by the theory of performativity, 'woman' as a gender category is viewed as something 'doing' instead of an inherent aspect 
of whom a person is (Butler 1988). In the context of the analysis part of this study, 'doing gender' is crucial to my understanding of gender as a social construction. Giving a discursive account of gender, I examined how women create and negotiate their gender identity.

\section{Research Design}

I used a case study approach with an in-depth individual interview method. The investigation of 'science identity development' constitutes the case of the analysis. In this study, the emphasis was not to measure, provide statistical information, or make predictions, but to achieve an in-depth understanding of a gender-science issue through individual experiences of women. Using this method in my research has facilitated a much deeper probing into the lived experiences of female science students and researchers, and how they constitute their own identities in relation to their disciplinary area, its norms, and expectations. I particularly chose semi-structured in-depth interviews as it was important for me to let the women voice their experiences themselves.

The boundaries of the case are geographical, temporal, and demographic: geographically the cases bounded by the four universities in the Dublin area. The cohort, in this case, was taken from women registered in physics and physical sciences disciplines at bachelor's and master's, Ph.D., and postdoctoral level in the academic year 2018/19. The disciplines of physics and physical sciences have been determined according to HEA (2017/18) statistics of a new entrance, enrolments, and graduates by level, the field of study, and gender. Within the scope of this research, only the academic disciplines of science at the university level which has the lowest women's participation were listed and included in the case: physics and physical sciences (not further defined).

My emphasis was on the women who were at an early stage of their academic careers because there are many leaks in the pipeline in this population according to the data report carried out by UNESCO (2015) which shows educational pipeline rates of women in science in Ireland. Also, according to a Study of Progression in Irish Higher Education (2014/15 to 2015/16), higher education dropouts and switching careers mostly happen in the early years of the education or career. I aimed to find out how the 'science identity' of women in their early (academic) career years in higher education impact on their sense of belonging in science and progressing in this field. Also, I aimed to look at each study/ career level in physics and physical sciences in higher education in order to see if the women's participated in this study attitudes and self-identification with science changes depending on their academic level.

As my study was not a longitudinal one in which I could observe the 'development of science identity' over a time period, I decided to include each study/early career level so that I could see the identity development 'in process' in at a single point in time. Rather than conducting repeated interviews with the participants over the years, I decided to do one interview with the participants at different study/career level. In that case, the structure of the individual interviews was cross-sectional. Looking at each level (BA, MA, Ph.D., and postdoc) at the same time allowed me to see the identity development process' over a short period of time.

Demographically it was intended to include female students and researchers from diverse backgrounds in terms of country of origin, age, and ethnicity where possible. 
My main aim was to capture diversity in the target group in order to see if they faced any barriers in science based on multiple overlapping social identities of women.

This study received ethical approval from the authors' academic institution. To preserve the anonymity of the participants, each of them was assigned a pseudonym. The interviews were conducted with 29 women. Out of 29 participants (age range 18-40 years), 11 were undergraduate students, 12 were graduate students, and 6 were postdoctoral researchers. Out of 29 participants, 13 of them came to Ireland from other countries to study and/or research.

The sampling I used was purposeful and self-selective oriented in that only women who met the criteria within physics and physical sciences across the four universities in Dublin and might be interested to participate were invited for the interview. The participants were recruited through getting contact with the faculty administrations as the gatekeepers. The interviews were conducted across three months (March-May 2019). The interviews were audio-recorded and ranged about $45 \mathrm{~min}$ and an hour and a half. The participants answered questions about their motivation about science, their view of a scientist; how they think about themselves as scientists/science students and/ or researchers; their experiences of doing science; and their experiences as a 'woman' and a 'scientist' within their scientific community.

\section{Data Analysis}

A hybrid method of discursive narrative analysis and thematic analysis is used in my data analysis. I employed a discursive narrative as it focuses on the interactive context of the interview, performance of identity, and a detailed examination of the talk (Taylor \& Littleton, 2006). This way, both I, as the researcher, and the participants would have an active role in terms of constructing the identities and giving meaning to them. After a comprehensive narrative analysis of the interviews, I conducted a thematic analysis in order to explore similarities, differences etc. across the data. I chose to transcribe all my interviews myself in order to hear the participants voice once again and hand-coded the data instead of using a coding software.

Each transcript was read as a story in order to become acquainted with the transcript set as a whole. Then, I read each transcript very carefully line by line in order to find the repeated words and phrases. I particularly paid attention to the common issues, terms, words, and phrases which participants used across their narratives. Based on the science identity framework used in this analysis, the transcripts were sorted into categories. Within the categories sorted before, the codes were allocated to the words and phrases commonly used by the participants. Then, the codes were combined to create the themes. Based on these methods, this study was organised into three major themes: 'belonging to science'; 'discourses of doing science-constructing the boundaries of a scientist'; and 'discourses of doing gender-negotiations of femininity in science'.

\section{Methodological Limitations}

The sample was limited to 29 women, so the results are not expected to be generalizable to all-female physics and physical sciences students and researchers. However, the readers may find similarities between the participants' and their own experiences, or 
they may gain insight and awareness of the lived experiences and perspectives of the participants' described.

Secondly, while there were a few participants from an underrepresented minority background such as sexuality, ethnicity, and religion (different than dominant scientist population) involved in the study, the participants were by no means a representative population of scientists. Ireland is relatively a small country. The research only took place in four Dublin universities and was limited to physics and physical science departments. It only reflects a small part of the big picture. Although Intersectionality was included in my theoretical perspective, the sample was more homogenous than I expected. For example, there was not much difference among the participants in terms of their socio-economical background. There was no participation from disabled people.

Thirdly, the participants were from various subfields of physics and physical sciences. In this study, I examined their 'science identity' to provide unity among the women who were in physics and physical sciences fields. However, I noticed that there are various constructions of 'science identity' depending on the disciplinary area of the participants. For example, as can be seen from the findings below, some of the physics students called themselves a 'physicist' rather than a 'scientist' by distinctively separating them. Some of them also sub-categorised 'physicist' identity by providing examples of 'energy physicist' from a 'medical physicist' from various constructions. One of the participants introduced herself as an 'astrophysicist' rather than a 'scientist'. This shows me the real diversity behind the label 'scientist'. Future studies can pay attention to these sub-fields by showing the differences and similarities across these identities.

Finally, future studies could replicate this study to examine women's science identity development by paying greater attention to a wider range of institutional contexts (e.g. type, size, geographic) and by including women from a wider variety of social/cultural backgrounds. Future research can also focus on longitudinal models of understanding science identity development, to understand how the concept of science identity might change over time.

\section{Findings}

\subsection{Belonging to Science}

'Science is not just what I do. It is exactly who I am' Sophia, $\mathrm{PhD}$

In the narratives of women, a sense of belonging centred on how they the participants about science and how they feel in a scientific community, in other words, the emotional and community attachment of women to science was examined.

\subsubsection{Emotional Attachment to Science}

All the participants indicated a great interest and enthusiasm for science regardless of their age, study/career level, and academic discipline. They used strong descriptive words to express their interest in their academic disciplines. (e.g. I am passionate about it, I fell in love with it, it is amazing, I love it, it is so cool, it is very interesting). 
The following narratives of the participants indicate a strong emotional connection to science.

I think the biggest thing that I bring to my study of physics is just my enthusiasm, my passion for it. (Molly, BA)

I love what I am doing. I feel that it is a part of my life. It is a way of life for me. (Carol, postdoc)

When I was in college, I realized that physics was very interesting, and it was pure accident that I got here, and then as the years went on, I fell in love with physics more and more. (Demi, BA)

Their interest was stimulated by their curiosity, a feeling of achievement, a feeling of enjoyment, and their mathematics and science competence from childhood or early school years.

It is something I am proud of. It is something I am passionate about. Since I was a child, I was very interested in how things worked. I really liked physics. I thought it was really cool and very interesting. (Kathryn, Ph.D.)

I had always thought that physics was my thing and it made me feel special. When I am feeling low and lacking confidence, I always remember my medals from my teenage years, and I say, God, I was the first and only girl in the country to win this. (Mia, postdoc)

Dora was different than the rest of the participants on the account of the fact that she enjoyed challenging the taboo around physics that 'not many people, especially not many girls do physics'. When asked why she particularly chose to study physics at college, she responded:

It was challenging, and I really liked that it was challenging and that in a way I kind of enjoy the taboo that was around it, not many people did physics, and then even more so not many girls did physics. I think, I kind of enjoyed that. (Dora, BA)

Along with the factor of interest, a sense of competence also affected the participants as a first step in establishing a science identity. Regardless of their disciplinary area, they all associated physical science (especially physics) with mathematics. Their interest in mathematics from their early years at school prompted them to study physical science-related disciplines at college. All the participants self-evaluated their mathematics and science competency in secondary school and for the leaving certification as above average. 'I have been always good at mathematics and science' was repeated by the majority of the participants during the interviews.

Physics is just very strongly linked with maths. People said I should do physics because I was good at maths. At the end of the day, I am very happy with what I have been able to do. (Dee, postdoc)

I loved applied maths and I was getting more into the physics subject. Physics just seemed really cool. It just seemed the most interesting and most fun way to do maths that I could think of. If I didn't love maths so much, I have never would have ended up in physics. (Lara, Ph.D.)

When I was younger everybody told me, I was good at maths. I really enjoyed maths, maybe I can specialize in something like fluid dynamics, which is very 'mathsy' heavy, very 'physicsy'. (Reese, BA)

As it can be seen from the narratives above, the participants associate themselves with the mathematical aspects of physics. They are competent with their mathematical skills 
which enables them to choose physics and/or physical sciences at college and build a strong identity related to it.

Later, in their college years, they were attracted by a variety of scientific activities: labs, discoveries, hands-on activities, experimental aspects of science, making things work, analytical, and practical works.

I always loved mathematics and science. I was very good with minimal effort. But when I actually stepped inside the laboratory to make an experiment, then I realized that I wanted to be a scientist. (Sophia, PhD)

I am always more interested in the hands-on stuff, so like experiments. I know from my experience in the industry during the internship, you do a lot of programming to try to make things work and stuff, which I think is really cool. (Nicole, BA)

Demi (BA) was the only participant who did not take any science courses prior to college. She first experienced physics at college and she completely loved it. She was part of a research group as an undergraduate student when we met for the interview. She was very proud of her participation in physics and of her ability. Demi enjoyed the experimental aspects of science, much like Sophia and Nicole.

I just continue and remind myself, Oh, yeah, I am doing this because I love this. I love discovery and I love science. And going into NASA, reading all their articles is so fascinating and interesting. So that one hour of a boring lecture, it means nothing in comparison to what I want to achieve. I have a goal and I just keep going for it. (Demi, BA)

\subsubsection{Community Attachment to Science}

The scientific community is a broad term that can be made up of scientists in academia, in academic conferences or industry (if they do an internship), of small working groups in the context of a classroom. It can also be a small group of friends who enjoy science and do it or a group of individuals who belong to a certain scientific discipline. My emphasis was on whether they are respected, supported, and accepted by other members of the scientific community, whether they feel they fit in, belong to, or are a part of these science groups, how comfortable they feel, and how they all influence their science identity development.

Most of the participants described science as 'team effort' and explained involvement in the scientific community with such phrases: building relationships with other members, sharing ideas, building a network, having good communication with people. Based on their explanations, I find out that women prefer the communicative and cooperative aspects of science. 'Supporting', 'sharing', and 'collaboration' were the keywords which were repeated many times in different contexts during the interviews. The narratives reveal that their motivation was positively shaped by a supportive and encouraging group of people within their scientific community and enabled them to have a strong science identity.

I had a very encouraging little group I high school where I really loved science. I was around people who loved science and saw the passion that I had. If I hadn't had the encouraging support system that I had as a teenager, I don't know if it would have ended up in physics. (Molly, BA)

For Molly, in her first two years of college, things changed a little. She described the physics environment at college 'not women heavy field'. She predicted it but still found it 
less encouraging. In her early years in college, she described that as a challenge, but once she found a support group much like she had at high school, she felt more comfortable.

When I was in my physics classes at college, I was aware that particularly physics is not a very woman heavy field. I guess it wasn't shocking to me, but at the same time, it was not overwhelmingly encouraging. I think that is particularly more of a problem earlier on.

Not many participants experienced such a supportive and encouraging science environment like Molly did. They mostly shared with me an ideal picture of the scientific community in their heads they would like to be engaged in or they wish to be a part of. From a gender perspective, the findings reveal that a feeling of 'fit in science' and getting meaningful recognition from scientific others as well as from other people was problematic for the women in this study because it depended on an external audience. Lou (postdoc) talked about the seminar she attended before our interview. The speaker, who was a very wellknown member of her research group, started talking about the future of the field and the key issue for him, as I quote what Lou said, 'the feminization of the field'.

He said that too many women were coming in and for him, women were not fit to go on the field, because they were not as strong as men. He also said we were doing too much modeling, we should not rely so much on computers and we should still go more in the field. At first, I was shocked to hear that. I felt super bad. I thought it was a joke at first. I was waiting for the end of the joke, he was super serious. So, I heard afterward that people were shocked by what he said, but nobody called him out.

The narrative of Lou is important as it specifically relates to prejudice based on gender in terms of being respected and valued in a science community. Also, some participants pointed to the gender discrimination in the academic conferences:

Sometimes some researchers or my advisor would talk more naturally to the guys in my department, even though they are Ph.D. students. I have realized that they would not look at me and they would talk to the guys even though I have more expertise on the questions they are asking. (Lou, postdoc)

I have worked really hard to be where I am, but they put me down because I am a woman. It is about the comments I hear, for example, when we were walking with our supervisor, people said oh you are all very well accompanied and kind of that we are all women when with one supervisor who is a man and kind of like we are just keeping him company or answering questions. (Ale, Ph.D.)

From an intersectional perspective, the feelings of isolation and alienation of racial, ethnical, and religious minority women in this study can be associated with uncomfortable feelings with the scientific environment as well as with being exposed to certain stereotypes (from both scientific and non-scientific others). For example, Jill (Ph.D.) described her social environment in her colleges as her 'comfort zone' as it is more international than the outside world. Even within her 'comfort zone', she needed to prove her scientific skills and abilities to be valued and accepted by scientific others in her department. Outside of college, she racially stereotyped as 'not a scientist' as people from her origin of country work in the service industry by a great majority in Ireland. The conversation between me and Jill is as follows:

Jill: They may judge you in the beginning, but then once they have seen your work, they are convinced by your work and they leave the stereotype behind. 
Researcher: What is the stereotype? Why do they judge you?

Jill: Because I am a woman and I am from a country that has a poor education. They probably don't know how my life and education were there.

Neha and Samiya (Ph.D.) claimed, similar to Jill, that while they enjoyed optics-related research, because of their ethnic and religious context, the social atmosphere made them uncomfortable.

I come from Bangladesh. When it comes to competing with European people or American people, they underestimate you. Even with my Ph.D., this is one struggling part because I think I am from that background, lots of people think that they know far better than me just because they are from developed countries. (Neha)

I feel like because of where I am from, my background, and like as a Muslim, I feel not very well integrated. ... It depends on the people. Some of them just pass by the way you look. They would not even stop and talk to you about your science just because of the way you look. (Samiya)

In this study, especially at the postdoctoral level, the participants saw themselves as capable scientists. They seemed confident in their identities as scientists and never questioned whether they 'fit in science' even though most of them questioned the complete inclusion of women in their disciplinary field or in general into scientific community. However, at undergraduate level, the participants seemed to be more affected by people within their academic circle. Dora (BA) said, 'I was always going to drop out of physics in the first year because of how everyone made me feel about myself'. She stressed her individual commitment to persist in science (physics in her case) even though the scientific community around her discouraged her.

\subsection{Discourses of Doing Science-Constructing the Boundaries of a Scientist}

'If I were to find myself, I would be a scientist, also a complete nerd geek.

That is what I defined this up'

Chloe, BA

Overwhelmingly, participants in this study described scientists as creative, hardworking, determined, dedicated, problem solver, passionate, curious, patient, and inquisitive. Regardless of their level of study and academic position, the scientist, from the viewpoint of the participants, is someone who works intensely on everything they do, who can go deep and never give up, who can think creatively, and most importantly, who loves science passionately.

The discourse of personality traits of a scientist seemed to be fit with the actual practices that participants engaged in and their actual work of doing science. For example, the participants who were doing a Ph.D. in Optics described their works as 'exacting' which demands 'hard work' and requires great 'patience' and effort. Neha who was a final of $\mathrm{Ph} . \mathrm{D}$. in Optics described her work as experimental which, in her own words, explained as such: 'I build my optical setup and I rebuild my system may be more than a hundred times to get like one result'. Her description of her Ph.D. project as high demanding and her description of a scientist as 'hardworking' and 'patient' showed that she constructed the personality traits of a scientist through her scientific work.

Another example is that Natalie (BA) described a scientist as a problem solver who solves physical problems such as making inventions and making things work. Natalie was 
doing an internship in an industry at the time of the interview. She said she was always interested in hands-on stuff and the experimental aspect of science. She constructed her description of scientists both through her interest and capability as well as through seeing scientists who 'make actual thing' during her internship experience.

Lara's description of a scientist is influenced both by the way she is herself doing science and the way other people are doing science around her. She expressed:

I do theoretical astrophysics. So, I just work at a computer all day. My view of what a scientist has changed so much. When I was a kid, I would have viewed a scientist as someone in a lab, someone building something, and they were usually a man I was picturing. Now I picture a scientist as just someone who is working away at a computer or trying to understand an issue for months on end. ... I think that is just because you base this on your environment or your influences. (Lara, Ph.D.)

Similarly, April stated that the physical image of the scientist in her head changed after she had seen different images of scientists around her. Just like Lara, April also described a scientist as someone who looked like her. She expressed:

I have seen so many different images of the scientists, so it is not like the old guy with crazy hair. I mean I have seen that, but that is not the typical image. It would be just kind of someone like maybe my age and doing research. (April, MSc)

The personality traits the participants attributed to a scientist was neutral. What I have concluded from their narratives is that science is a process that you can learn and contribute to the way of creating something. The participants' passion for science comes from their enjoyment of doing science and the inquisitive nature of science no matter how hard the scientific route/task can be. For this reason, they described the characteristics of a scientist as creative, passionate, hardworking, dedicated, curious, and patient.

The narratives that emerged from the data showed that the physical appearance of a scientist is gendered and stereotyped in contrast to the personality traits of a scientist. Most of the participants described the physical appearance of a scientist as such: 'old white men in senior position', 'man in a lab coat fuzzy Albert Einstein hair', 'crazy old bald scientist', 'crazy white men', 'Einstein kind of the old dude'. From these descriptions, I can see that the stereotypical image of a scientist is racialised, gendered, and aged, described as crazy, as someone in a senior position and inspired by a famous physicist. They established the description of a scientist based on what they have seen from their science environment (e.g. men in senior positions), popular media (old white men in a lab coat), and influential agents of science (Einstein).

I think the stereotype is like Albert Einstein, white hair glasses. That is probably the image. I have to say that when you go to some conferences that the majority of people are old, white men and they are in those senior positions. (Aine, Ph.D.)

A crazy, old, bald scientist, boring all about it... old crazy white men when you think of physicists. (Nicole, BA)

Popular media portrayal of scientists still often presents them in stereotypical waysas 'crazy-haired, old White boffin males, wearing lab coats, and probably glasses' (Archer \& DeWitt, 2016, p. 60). In their narratives, women did not directly blame the media for not representing people from a diverse background in science. However, I interpreted some of their narratives closely linked with the stereotypical portrayal of 
scientists in media. Some of the participants drew upon examples from the TV show Big Bang Theory (nerdy geek masculinity), Nobel prizes (overwhelmingly white men), and NASA space stuff (a lot of men at desks and a lot of the big shots in space signs are men, middle-aged and White).

Even though I wouldn't look like so, people consider me very nerdy. I like it. A real one, like the one who does all the things in the Big Bang Theory. (Sophia, Ph.D.)

The findings revealed that in women's narratives, the stereotypical image of a scientist was overwhelmingly masculine; however, it was not a sign of acceptance. Instead, it was a criticism of a dominant masculine culture of science. Some participants mentioned that the stereotypical image was replaced by the construction of a scientist themselves after they academically engaged in science. This shows that they added their understanding when they actively participate in scientific works. Some of them challenged the stereotypical image by giving an example from their appearance. Dora (BA) was one of them:

Dora: When I first came into the class, I felt like the boys are kind of looking at me like, what is she doing here? I am not a typical girl in physics.

Researcher: What is the typical physics girl?

Dora: I think the one that, you know, is seen by everyone is just someone who doesn't look like me. When it comes to a woman, it is someone who maybe doesn't care so much about her appearance. ... whenever I look around, I have just seen typical physicist girls, that is fine. That is just how it is.

She noticed that the subject role of a stereotypical physicist girl was one way to be accepted as a physicist girl in her academic circle. Otherwise, people 'look at you like what you're doing here'. Later in the interview, she said, 'getting through four years in the physics department at college, you have to have very tough skin'. This is the way Dora would stand out from the physics community around her (having tough skin). Another way that Dora could position herself as a recognised physicist girl was to fulfil the physicist's subject position by being involved as someone who breaks the boundaries of 'typical physicist' in the physics community.

I want to be very active in the physics community so people can look up and see this is a girl that is, you know, do all of this. She has been through all this, and it is not as a typical physicist.

Some of the participants compared a scientist with a physicist. Despite identifying the physicist as a 'man', they described a scientist as a 'person' saying that a biologist or a chemist can often be a woman. They categorised the branches of science as more masculine or as more feminine. One of the participants, Demi, even categorised the subfields of physics according to a gender saying that a medical physicist can be a woman, but an energy physicist is always a man. She was the only woman who was studying in the energy field of physics at that time.

An image of scientists... If there is a woman, I would think that she is a biologist and I would think that she is a medicinal chemist, or I would think that she is a medicinal physicist. I would not think that she is, you know, a physicist like an energy physicist. We have some brilliant women, but it is mainly men. (Demi, BA)

Diane and Julianne also attributed neutral features to scientists and physicists when they only described the personality traits of a scientist. However, when they described physical 
image, both of them separate between a scientist and a physicist in terms of the image in their heads.

I guess like when I think of just the term scientist, I would probably picture biologists and maybe a woman. But if I am picturing a physicist, I would picture a man. When people are talking of discoveries, it is just like male names. When people ask me what I do, it is always in my mind that I am a girl and they are not expecting me to do physics. That is what bothers me. (Julianne, Ph.D.)

When you say physicist, that has a slightly different like stereotypical image in my head than a scientist does. When you said scientist, I was thinking, just a person, white coat and you know they are researching, and they are working hard. But when you said physicist, it suddenly became a man in my head. I probably think more of my lecturers here who tend to be like a male, very assertive in their opinions. (Diane, BA)

Diane (BA) portrayed the image of physicists that relied heavily on the lecturers in her field, but this description was in contradiction to her self-identification as a physicist. In other words, there was a contradiction between the discourses Diane constructed herself as a physicist and the ways that she depicted images of physicists.

I would call myself a physicist because I like physics more than I intend on doing other sciences. You need to be a good mix of logic and creativity and know when to apply logic and where to. (Diane, BA)

Some of the participants positively accepted the 'nerd geek' stereotypical image as they were personally lean towards this label while some of them attributed a negative meaning to it saying that the label harms women as the 'nerd geek' image is viewed as more masculine. Based on their experiences, their positioning, and the current situations of the participants. Even though the stereotypical scientists mostly tended to me white western males in their narratives, they attempted to challenge it in an improvised way (at the time of the interview) in ways that constructed new positioning.

\subsection{Discourses of Doing Gender-Negotiations of Femininity in Science}

\section{'It's all in your head'}

Annie, BA

The narratives under this theme describe the participants' understanding and experience of their gender identity, how they perform their gender, and their perception of womanhood as well as how they define and demonstrate their gender within the context of science.

Analysis of the interview data suggests that what it means to be a woman is quite subjective and complicated. As one of the participants, Reese (BA) said: 'I am perfectly fine fitting within my description of a woman', each of us can create our space (positioning) in defining, expressing, and acting our gender. Most of the women I interviewed described 'woman' according to their specific positionality, attitudes, and experiences. Through the analysis of the interviews, I understand that 'woman' is a fluid and flexible term. As Dora (BA) said, 'it is just like 'love' which is changeable over time'.

The reasons why someone loves you can be something at some point in time and then years later they can be different. I think it is the same thing. You know, what makes you a woman is very dependent on your experiences. (Dora, BA) 
Dora's expression of her gender identity as a 'woman' are in line with her 'physicist' identity. In the following narrative, she identifies herself with a 'strong physicist woman'. This phrase shows that there is a mutual positive interaction between her science and gender identities. These two identities empower one another which in the end makes her develop a strong science identity as a woman.

I do feel very strongly about being a woman. I think it comes hand in hand with being a physicist. If I was to describe myself, I would say a strong physicist woman

Some participants reported that her attitudes to 'woman and feminine' changed after she went into physics. April was one of them:

My gender, my role as a woman is changing. When I was in secondary school, being a girl was like kind of..., I thought like I would go into biology, then I suppose as I became more into physics and stuff, I was like, oh, I can be a girl and do physics. I don't know if my gender changes or if just the context of how I see my gender. (April, MSc)

In terms of showing the fluidity of gender identity within the science context, Chloe (BA) is an interesting example. She mentioned that she rejected a certain gender identity (girl) in her childhood as she tried to fit into 'boy' with which 'science skill' is related, but as she got older, she both enjoyed 'looking like a woman' (physical expression) and doing physics.

When I was a kid around 8 to 10 , I had this serious phase where I wanted to be a boy. I felt so alienated by the girls because I was deeply interested in all of these things that were primarily boys' things, science, dinosaurs, robots, all of that. When you grow up you sort of realizing that, you know, I want to be me. There are many deeper things I would say. I am happy being a woman. I do like being a woman physically and visually as in my mind, my body, I like it. (Chloe, BA)

What Chloe mentioned was mirrored in Demi's (BA) narrative. She said she had a lot of male traits, inspiration, and humour: 'I feel like I am not a very girly girl and maybe that's why I fit physics so much because I am not that feminine if you understand'. Demi associated herself with masculinity, which, for her, relieved the friction between her visual self and physics.

I am young and I go out to clubs and things like that and you know if I do my hair and I do my makeup, I dress nice and I meet someone they asked me first of all if my name is real, second of all they asked me if I am actually doing science. (Demi, BA)

In Demi's case, even though she is reinforcing the idea of 'girls need to have masculine traits in order to be in physics', the masculinity itself is diversified by her performing femininity visually.

The participants referred to the complicated relationship between the expression of femininity and being valued, respected, and recognised in science. Shalini has explained that when you care about your appearance, people have a judgment about you. She emphasises that her performances of femininity orienting around wearing make-up and dressing up cannot be interpreted as evidence of a lack of interest in science.

People think that just because I am dressing up or just, you know, I have a lipstick on my lips that means that I am more interested in fashion rather than in science, which is not true. It makes me feel good. (Shalini, MSc) 
Lou (postdoc) supported Shalini's criticism of the attitude of people towards the relationship between femininity and science by saying, 'If you are too feminine then it is also a problem. Like people would not take you seriously'. For Kathryn, the world of science reflects society. She said she said that she has to dress professionally when she goes to a conference. She added that she was avoiding wearing 'too girly of clothing'.

I feel like I should not wear too girly of clothing, which is silly because it is equally professional to be a girl. When you are in an environment surrounded by so many men, it is hard to know how to be a woman in that environment and still be respected. Would they still respect me if I was wearing a lot of makeup, would they still respect me if I was wearing loads of fancy dresses? I don't know. (Kathryn, Ph.D.)

Diane (BA) commented that as a woman you sometimes make sacrifices from your femininity in a scientific environment such as labs. She described the laboratory as a kind of male space in which when you try to perform femininity, you might be alienated. For example, the typical clothing in the labs, from Diana's perspective, are masculine rather than neutral. She described how people look in the labs with their skin covered, hair off, and certain shoes as 'masculine'.

You would get laughed out of it a little bit if you tried to start a conversation about clothes or hairstyles. That's just not a conversation you have in that context because it is quite male space. (Diane, BA)

For Diane, just like most of other participants, the identities of 'woman' and 'scientist' empower each other.

I sort of in some way I enjoy that I am a woman and a scientist. That is a strange combination because I like showing that it is possible and then I can be good at both. (Diane, BA)

Some of the participants associated femininity with emotions and traditional women's role which make women 'multitasking' and 'stronger'. Neha $(\mathrm{PhD})$ sees women as more emotionally powerful and multitasking than men, as she has to think about home and work in the laboratory, for instance, while men don't have to think like that. Shalini identified herself as 'proud to be a woman' and 'really into science' when she was talking about her science and gender identities.

Being a woman gives you a lot of strength, especially in science. You can't ignore the fact that women's lives are really very complicated and different from men's lives. You've got a hundred things to focus on at one point. It is very difficult sometimes (Shalini, MSc)

Just like Neha, Shalini also thinks that dealing with different tasks at one time is empowering for women although it may be very difficult. Her scientific identity is inspired by her being a multitasking woman.

Based on the narratives of the participants, it was found that, how they position their gender within science differs depending on their individual experiences, feelings, and attitudes about gender-specific roles. 


\section{Discussion}

To answer the research question 'How do female students and early career researchers in physics and physical sciences fields in higher education construct their science identity related to their gender identity?' I can claim that the science identities of women who participated in this study were experienced and constructed in many ways.

From their early years, their curiosity and enthusiasm for science and the feeling of competency have a positive effect on their motivation to advance in the scientific field and to create a positive identity for science. This finding is consistent with Potvin and Hazari (2013) result that interest is central to science identity.

In previous studies, it has been found out that young people tend to associate most science careers with masculinity (Archer et al., 2012), with children perceiving science as being for boys (Francis et al., 2017). In another study conducted in Ireland (McLoughlin et al., 2015), it was found out that $44 \%$ of students identified the perception that STEM subjects are more suited to males than females. This study result of McLoughlin et al. is in line with Archer et al.'s study. Some participants in this study established a connection between masculinity and science especially in their early years and before they academically engaged in science. Participants who were studying or studied physics often emphasised 'the fewer number of girls' choosing physics class compared to the girls choosing other science courses at school. Here, I would particularly like to emphasise the phrase of Lara (Ph.D.) to explain the feeling of isolation when your interest is different from what society expects your interests to be. "no one wants to do the subject they love if they feel like they are going to be like an outsider'. Her statement says so much about how important it is for individuals to love anything to sustain it. Breaking expectations is difficult when your desires and talents vary from what society expects. I claim that physics and physical sciences which are still seen as traditionally masculine and hard domains need a strong interest. The high level of interest and passion described by the participants enabled them to progress in science as can be reflected from Neha's (Ph.D.) statement: 'I love it. Otherwise, I wouldn't survive that long. Being a scientist is like my passion'. The participants were inspired and encouraged by their intense excitement along with their pleasure of accomplishment and sense of achievement on the way to establishing their identities in science.

When it comes to community attachment to science, how the participants feel recognised, valued, respected, and accepted by scientific others within their science community as well as other people around them were also expressed to be a contributing factor to form a science identity. Some of the participants discussed their science identities in comparison to others (e.g. their friends, colleagues, people in higher positions). This is where their gender and other intersecting identities appeared more. From a gender perspective, the findings reveal that a sense of 'fit in science' and positive recognition from people within their scientific community, as well as other individuals, was problematic for women because it relied on an external audience. The majority of the participants stated that they received a sign of shock or surprise from other people when they introduced themselves as a scientist (particularly a physicist) especially if they have (intersecting) underrepresented minority status. In the context of a college setting, at the undergraduate level, the participants compared themselves with their male friends in terms of getting equal opportunity (one of the participants said boys in her class were placed for internship positions earlier than the girls even if some girls had the higher grades), sense of self-confidence and proving their scientific skills. At a master's and Ph.D. levels, some participants expressed their frustration upon hearing sexist comments from other people in the conferences. They also stated that 
they felt isolated from the rest of the science community in conferences as the majority were white men in senior positions. Also, at the Ph.D. and postdoctoral level, the participants complained that there are few women in their research group or top roles within their faculty. As Kathryn (Ph.D.) said, 'It is hard to explain to someone how you feel weird. If you are the only one you feel like you are representing the whole gender'. I have concluded from their narratives that it allows them to feel a greater sense of belonging when women see other women within their academic and scientific community.

Good et al. (2008) have suggested that the feeling that one fits in, belongs to, or is a member of the academic community influence college students' intent to pursue related discipline in the future. In their study which focuses on math identity, they found out that women's lowered sense of belonging negatively influenced their intention to pursue a future mathematics career. However, their math ability was found out to protected women from negative stereotypes, allowing them to maintain a high sense of belonging in math and the intention to pursue math in the future. In my study, it is the individual passion and interest in science along with a feeling of accomplishment that allows women to continue despite their diminished community sense of belonging. They made a personal connection between their field and themselves rather than their personal relationship with scientific others and their science identity.

Consistent with previous studies (Kim et al., 2018; Brown, 2004; Robinson et al., 2018), it has been found that science identity is an ongoing and actively engaged process. The participants construct, develop, and perform their science identities by actively participating in scientific activities, interacting with colleagues and broader disciplinary communities, demonstrating scientific skills, and defining and shaping what and who a scientist is. For this reason, how they view scientists and how they view themselves as a scientist is highly important in influencing (shaping) how they do science. I have found out a strong connection between how they describe themselves as a scientist and how they do science.

In a study by Archer et al. (2010), it was revealed that most of the children (aged 10-11) reported enjoying science at school and this enjoyment was predominantly framed in terms of the practical mastery of 'doing science'. Their research also demonstrated that although they enjoy science, they may still see it as 'not for me' and choose not to study it at a higher level. In my study, the focus group was women who had already developed a certain degree of interest in the field of science. They all expressed their strong interest in science both in their early school years and later in their college years. Similar to Archer's findings, they all reported a strong connection between doing science and enjoyment of it. That is an important factor in shaping their science identity. Differently, in my study, they also reported a connection between how they view a scientist by personality traits (description of a scientist) and how they do science (doing/practicing science). This connection which may be developed in early years or later in college years can be regarded as a strong factor that keeps them engaging in scientific activity and building a science identity.

Analysis of the data showed that the physical appearance of a scientist is gendered and stereotyped in contrast to the personality traits of a scientist. They have reported that a stereotypical picture of a scientist, which is heavily white and male in senior position and working in a lab, discourages them but they also question and try to challenge it. This finding is consistent with Lederman et al.'s (2001) description of a stereotypical image of a scientist as 'white, middle/upper class, solitary laboratory-oriented man'. While widespread stereotypes of scientists and physicists persist among the participants especially at the undergraduate level, they have the potential to change stereotypes by participating in science as who they are. This can be seen in the narratives of the participants that once 
they are more engaged in science, they create their own image of a scientist that is comparable to how they do science. Gee suggests $(2000$, p. 86$)$ that 'there is a reciprocal relationship between a person and a social group and its core defining activity'. The complexity of these relationships makes 'identity' alive, fluid, and ever-changing. Accordingly, I argue that when women engage in science and constitute their science identities, they redefine the values and norms in science, they expand the definition of a 'scientist', and they change the particular characteristic of a scientific community.

The role of gender in constituting the participants' science identities varies depending on their particular experiences, standpoints, and how they make sense of their gender. For example, some of the participants stated that women's traditional gender roles which crash women's science careers make women 'multitasking' and 'strong'. In these narratives, (physical) science which is regarded as the 'masculine' and 'hard' domain (Francis et al., 2017) seemed to conflict with traditional views of women's role in society and the home. While women's gender and science identities were addressed as sometimes overlapping (and conflicting) across the narratives of the participants, they have also indicated that women are blessed with multitasking skills that enable them to be able to handle both identities.

For some participants, their identity as 'young woman doing physics' makes them feel 'independent' and 'strong'. Their identification and engagement with science strengthen their 'woman' identity and vice versa. In these narratives, I have noticed gender and science identities go hand in hand. And I feel that girls resist/challenge the tension between the subject position of a 'scientist' and the subject position of 'woman' by making a positive and reinforcing connection between their science and gender identities. In their case, being a 'woman' and a 'scientist' positively affect each other.

In Archer's (2012) study which focuses on elementary school girls' science identity construction, it is stated that doing girl and doing science identity is difficult to achieve as 'science aspirations sit in an uneasy tension with femininity and must be continually carefully negotiated and defended against challenges from wider popular discourses which align science with masculinity' (p. 983). In my study, the performances/practices of femininity and masculinity have been intertwined in most situations. For example, some of the participants enjoy performing femininity on the body but reject feminine features or vice versa. They have described themselves as 'feminine' dressed in 'womanly' clothing, but they have questioned and rejected feminine personality characteristics, as for them it may crash with their science identity. Some others have stated that they feel feminine inside but perform masculinity. One of the participants said she was proud to look girly and to be a scientist which is an unusual mix for her. Thus, I claim that there are multiple ways of performing femininity and masculinity within the context of science. In certain cases, women have reported compromising the femininity in order to fit into science. In their own words, they 'have to make sacrifices for one or the other' (being a woman and a scientist). For example, they complained about the dress code in conferences and labs in which feminine clothing is deemed 'not professional' while 'typical men's outfit' is considered professional and appropriate. On one side, by adapting themselves to the conference and laboratory setups, they absorb and proceed on masculine norms, otherwise as Kathryn (PhD) said that if they wore make-up and fancy dress, it is a matter of whether they are still respected and recognised as a scientist. On the other side, as they enjoy being a woman and a scientist which is described by Diane (BA) 'a strange combination' and they want to show that it is possible.

Similar to dressing up, make-up also described as a 'feminine' structure by the participants. The research by Banchefsky et al. (2016, p. 106) suggest that 'wearing make-up 
may be viewed as particularly incompatible with STEM careers because it suggests that a woman puts too much effort or time into her appearance'. In this study, the women challenge the tension between looking feminine and doing science. As Annie (Ph.D.) puts it, 'I am a very feminine girl, also fantastic at science, but I don't feel I necessary to do either. I just do what I feel. And if it bothers someone, it bothers someone'.

Another important issue is that women are double stereotyped in science when gender intersects with their other social/cultural identities. The participants have stated that if 'you are not white, man and western', you feel like you need to prove your scientific skills in order to be recognised as a scientist. 'Once they are convinced by your work, they leave the stereotype behind' said Jill (PhD). This finding supports the argument made by Banchefsky and Park (2018) that the negative ideologies position the dominant subgroups-White men-as superior and normative, further marginalizing women and racial minorities. Thus, increasing the number of underrepresented groups in science is important in terms of eliminating negative ideologies and stereotypes towards minority groups. Stets and Burke (2014) claim that identity verification, which means having to do with social belongingness and integration, including being accepted and valued, is central in the identity process. So, for a scientist, being valued, accepted, and known by significant others are important in terms of increasing the sense of belonging and identifying themselves with the science identity.

\section{Conclusion}

I simultaneously explored women's gender and engagement in science through their narratives. Even though women were influenced by the dominant idea of physics and physical sciences as being white and masculine, they challenged the dominant system of science identity by transforming it and by blurring the boundaries of what and who a scientist is. The process of constructing a science identity may lead to stress because science identity is not always consistent with 'woman'. Criticizing the male stereotype of a scientist, I noticed women often broke this stereotype by trying to remove the clear borderline of 'scientist' and 'woman' through their everyday experiences. Their struggles and the challenges of the masculine structure of science are both individual and collective. They want to 'exist' and become 'visible' as who they are. I would suggest that the content of the 'being a scientist' construction has shown an interplay of discourses of doing and enjoying science, enthusiasm, competency, participation to a larger scientific community, and gender within the everyday construction of science.

The women's narratives in this study revealed (in)visibility and (under)representation concerns of students and researchers in physics and physical sciences. The science education programmes in these academic fields should both train the students to be a scientist and to educate them about the culture of science. A suggestion arising from this study could be that gender studies can be implemented in science studies at all levels in Ireland. The interdisciplinary perspective of gender studies can offer an alternative way of looking at the sciences and science education as a starting point to challenge the prevailing practices of doing science and research as well as to challenge the masculine norms and negative stereotypes in science. Evidence from this study pointed to a need for institutions of improving ways of more inviting environments for women from minority backgrounds. In this study, participants from minority backgrounds stated that their scientific knowledge and skills are underestimated as if they were 'less educated'. To address this issue, students 
and faculty members can complete anti-bias training early in their educational journeys or careers.

Finally, the results of this study could be useful for girls considering a physical science major at college and women considering a science career in academia. These experiences could hold important details about creating an academic culture for science disciplines that embrace diversity and implement gender equality and inclusion in their policies.

Acknowledgements The analysis of this paper was drawn from one of the main research question of 3-year Ph.D. research entitled 'Science and Gender Relations: The Development of Science Identity of Female Students and Early-career Researchers in Higher Education'.

I am grateful to the women who participated in this study for moving this research forward by sharing their lived experiences, views, and suggestions.

Funding Open Access funding provided by the IReL Consortium

Data Availability The data for this article are confidential. The data generated during and/or analysed during the current study are available from the corresponding author on reasonable request.

Code Availability (Software Application or Custom Code) Qualitative data coding was used. The documents which show the coding can be provided upon request.

\section{Declarations}

Ethics Approval This study received ethical approval from the authors' academic institution.

Consent to Participate (Include Appropriate Statements) Informed consent was obtained from all individual participants included in the study.

Consent for Publication (Include Appropriate Statements) The participants have consented to the submission of the case report to the journal.

Conflict of Interest The author declares no conflict of interest.

Open Access This article is licensed under a Creative Commons Attribution 4.0 International License, which permits use, sharing, adaptation, distribution and reproduction in any medium or format, as long as you give appropriate credit to the original author(s) and the source, provide a link to the Creative Commons licence, and indicate if changes were made. The images or other third party material in this article are included in the article's Creative Commons licence, unless indicated otherwise in a credit line to the material. If material is not included in the article's Creative Commons licence and your intended use is not permitted by statutory regulation or exceeds the permitted use, you will need to obtain permission directly from the copyright holder. To view a copy of this licence, visit http://creativecommons.org/licenses/by/4.0/.

\section{References}

Alcoff, L. M., \& Kittay, E. F. (2007). Introduction: Defining feminist philosophy. The Blackwell Guide to Feminist Philosophy (pp. 1-13). Blackwell Publishing.

Archer, L., \& DeWitt, J. (2016). Understanding young people's science aspirations: How students form ideas about 'becoming a scientist.'. Routledge.

Archer, L., DeWitt, J., Osborne, J., Dillon, J., Willis, B., \& Wong, B. (2010). "Doing” science versus "being" a scientist: examining 10/11-year-old schoolchildren's constructions of science through the lens of identity. Science Education, 94(4), 617-639.

Archer, L., DeWitt, J., Osborne, J., Dillon, J., Willis, B., \& Wong, B. (2012). "Balancing acts": Elementary school girls' negotiations of femininity, achievement, and science. Science Education, 96(6), 967-989. 
Banchefsky, S., \& Park, B. (2018). Negative gender ideologies and gender-science stereotypes are more pervasive in male-dominated academic disciplines. Social Sciences, 7(2), 27.

Banchefsky, S., Westfall, J., Park, B., \& Judd, C. M. (2016). But you don't look like a scientist!: Women scientists with feminine appearance are deemed less likely to be scientists. Sex Roles, 75(3), 95-109.

Brown, B. A. (2004). Discursive identity: Assimilation into the culture of science and its implications for minority students. Journal of Research in Science Teaching: The Official Journal of the National Association for Research in Science Teaching, 41(8), 810-834.

Butler, J. (1988). Performative acts and gender constitution: An essay in phenomenology and feminist theory. Theatre Journal, 40(4), 519-531. https://doi.org/10.2307/3207893.

Butler, J. (2015). Judith Butler on gender and the trans experience: "One should be free to determine the course of one's gendered life” (Cristian Williams, Interviewer). https://www.versobooks.com/blogs/ 2009-judith-butler-on-gender-and-the-trans-experience-one-should-be-free-to-determine-the-courseof-one-s-gendered-life. Accessed 20 June 2019.

Cardwell, M. (2014). Dictionary of psychology. Routledge.

Carlone, H. B. (2012). Methodological considerations for studying identities in school science: An anthropological approach. In Varelas, M. (Ed.). Identity construction and science education research: Learning, teaching, and being in multiple contexts (pp. 9-25). 35. Sense Publishers.

Carlone, H. B., \& Johnson, A. (2007). Understanding the science experiences of successful women of color: Science identity as an analytic lens. Journal of Research in Science Teaching, 44(8), 1187-1218.

Cheryan, S., Ziegler, S. A., Montoya, A. K., \& Jiang, L. (2016). Why are some STEM fields more gender balanced than others?. Psychological Bulletin. Advance online publication. https://doi.org/10.1037/ bul0000052.

Code, L. (2007). Feminist epistemologies and women's lives. Alcoff, L.M. and Kittay, E. F. (Eds.) The Blackwell Guide to Feminist Philosophy. (pp. 211-234). Blackwell.

Code, L. (2014). Feminist epistemology and the politics of knowledge: Questions of marginality. The SAGE Handbook of Feminist Theory (pp. 9-25). SAGE Publications.

Espinosa, L. (2011). Pipelines and pathways: Women of color in undergraduate STEM majors and the college experiences that contribute to persistence. Harvard Educational Review, 81(2), 209-241.

Francis, B., Archer, L., Moote, J., DeWitt, J., MacLeod, E., \& Yeomans, L. (2017). The construction of physics as a quintessentially masculine subject: Young people's perceptions of gender issues in access to physics. Sex Roles, 76(3-4), 156-174.

Freeman, T. M., Anderman, L. H., \& Jensen, J. M. (2007). Sense of belonging in college freshmen at the classroom and campus levels. The Journal of Experimental Education, 75(3), 203-220.

Fryer, D. R., \& Wilchins, R. (2012). Thinking queerly: Race, sex, gender, and the ethics of identity. Paradigm Publishers.

Gee, J. (2000). Identity as an analytic lens for research in education. Review of Research in Education, 25, 99-125. https://doi.org/10.3102/0091732X025001099.

Gisler, S., Kato, A. E., Lee, S., \& Leung, D. W. (2018). One size does not fit all: Gender inequity in STEM varies between subfields. Industrial and Organizational Psychology, 11(2), 314-318.

Godwin, A., Potvin, G. (2017). Pushing and pulling Sara: A case study of the contrasting influences of high school and university experiences on engineering agency, identity, and participation. Journal of Research in Science Teaching, 54(4), 439-462. https://doi.org/10.1002/tea.21372.

Gonsalves, A. J., Danielsson, A., \& Pettersson, H. (2016). Masculinities and experimental practices in physics: The view from three case studies. Physical Review Physics Education Research, 12(2), 020120.

Good, C., Aronson, J., \& Harder, J. A. (2008). Problems in the pipeline: Stereotype threat and women's achievement in high-level math courses. Journal of Applied Developmental Psychology, 29(1), 17-28.

Good, C., Rattan, A., \& Dweck, C. S. (2012). Why do women opt out? Sense of belonging and women's representation in mathematics. Journal of Personality and Social Psychology, 102(4), 700.

Hazari, Z., Sadler, P. M., \& Sonnert, G. (2013). The science identity of college students: Exploring the intersection of gender, race, and ethnicity. Journal of College Science Teaching, 42(5), 82-91.

Hazari, Z., Sonnert, G., Sadler, P. M., \& Shanahan, M. C. (2010). Connecting high school physics experiences, outcome expectations, physics identity, and physics career choice: A gender study. Journal of Research in Science Teaching, 47(8), 978-1003.

HEA. (2016). HEA National Review of Gender Equality in Irish Higher Education Institutions. http://hea. ie/assets/uploads/2017/06/HEA-National-Review-of-Gender-Equality-in-Irish-Higher-Education-Insti tutions.pdf. Accessed 14 January 2019.

HEA Statistics Archive. (2017/18). Retrieved from http://hea.ie/statistics-archive/2017-18-graduates/.

Herrera, F. A., Hurtado, S., Garcia, G. A., Gasiewski, J. (2012). A model for redefining STEM identity for talented STEM graduate students. Paper Presented at the American Educational Research Association 
Annual Conference. http://www.heri.ucla.edu/nih/downloads/AERA2012HerreraGraduateSTEMIde ntity.pdf. Accessed 7 September 2019.

Kalender, Z. Y., Marshman, E., Schunn, C. D., Nokes-Malach, T. J., \& Singh, C. (2019). Why female science, technology, engineering, and mathematics majors do not identify with physics: They do not think others see them that way. Physical Review Physics Education Research, 15(2), 020148.

Keller, E. F. (1985). Reflections on gender and science. Yale University Press.

Keller, E. F. (1987). The gender/science system: Or, is sex to gender as nature is to science? Hypatia, 2(3), 37-49. http://www.jstor.org/stable/3810121. Accessed 7 September 2019.

Kim, A. Y., Sinatra, G. M., \& Seyranian, V. (2018). Developing a STEM identity among young women: A social identity perspective. Review of Educational Research, 88(4), 589-625. https://doi.org/10.3102/ 0034654318779957.

Lane, K. A., Goh, J. X., \& Driver-Linn, E. (2012). Implicit science stereotypes mediate the relationship between gender and academic participation. Sex Roles, 66, 220-234. https://doi.org/10.1007/ s11199-011-0036-z.

Lederman, M., \& Bartsch, I. (2001). The Gender and Science Reader. NY \& London: Routledge.

Lloyd, G. (1996). Reason, science and the domination of matter. Keller, E. F. \& Longino, E. H. (Ed.) Feminism and science (pp. 41-53). Oxford University Press.

McLoughlin, E., Fee, S., \& McCabe, E. (2015, December). The environment for women in physics in Ireland. In AIP Conference Proceedings (Vol. 1697, No. 1, p. 060025). AIP Publishing LLC.

Mooney, C., Becker, B., Salmon, L., \& Mangina, E. (2018, May). Computer science identity and sense of belonging: a case study in Ireland. In 2018 IEEE/ACM 1st International Workshop on Gender Equality in Software Engineering, (GE) (pp. 1-4).

Murphy, M. C., Steele, C. M., \& Gross, J. J. (2007). Signaling threat: How situational cues affect women in math, science, and engineering settings. Psychological Science, 18(10), 879-885.

Nosek, B. A., Banaji, M. R., \& Greenwald, A. G. (2002). Math $=$ Male, Me $=$ Female, Therefore Math $\neq$ Me. Journal of Personality \& Social Psychology, 83(1), 44-59.

Potvin, G., \& Hazari, Z. (2013). The development and measurement of identity across the physical sciences. In Proceedings of the Physics Education Research Conference (PERC).

Robinson, K. A., Perez, T., Nuttall, A. K., Roseth, C. J., \& Linnenbrink-Garcia, L. (2018). From science student to scientist: Predictors and outcomes of heterogeneous science identity trajectories in college. Developmental Psychology, 54(10), 1977.

Spencer, S. J., Steele, C. M., \& Quinn, D. M. (1999). Stereotype threat and women's math performance. Journal of Experimental Social Psychology, 35(1), 4-28.

Spongberg, M., Curthoys, A., \& Caine, B. (2005). Companion to women's historical writing. Palgrave Macmillan.

Steele, C. M. (1997). A threat in the air: How stereotypes shape intellectual identity and performance. American Psychologist, 52(6), 613-629.

Stets, J. E., \& Burke, P. J. (2014). Self-esteem and identities. Sociocultural Perspectives, 57(4), 409-433.

Schiebinger, L. (1993). Women in science: historical perspectives. In C. M. Urry, L. Danly, L. E. Sherbert, and S. Gonzaga (Eds.), Women at work: A meeting on the status of women in astronomy (p. 11). Proceedings of a workshop held at the Space Telescope Science Institute, September 8-9, 1992.

Schiebinger, L. (2000). Has feminism changed science? Signs, 25(4), 1171-1175. www.jstor.org/stable/ 3175507. Accessed 7 September 2019.

Smith, J. L., Lewis, K. L., Hawthorne, L., \& Hodges, S. D. (2013). When trying hard isn’t natural: Women's belonging with and motivation for maledominated STEM fields as a function of effort expenditure concerns. Personality and Social Psychology Bulletin, 39(2), 131-143.

Smyth, F. L., \& Nosek, B. A. (2015). On the gender-science stereotypes held by scientists: Explicit accord with gender-ratios, implicit accord with scientific identity. Frontiers in psychology, 6, 415.

Sowell, S. P. (2004). Doing gender/teaching science: A feminist poststructural analysis of middle school science teachers' identity negotiations. (Doctoral dissertation). https://diginole.lib.fsu.edu/islandora/ object/fsu\%3A176123/. Accessed 10 December 2019.

Stout, J. G., Ito, T. A., Finkelstein, N. D., \& Pollock, S. J. (2013). How a gender gap in belonging contributes to the gender gap in physics participation. In AIP conference proceedings, 1513(1), 402-405.

Taylor, S., \& Littleton, K. (2006). Biographies in talk: A narrative-discursive research approach. Qualitative Sociology Review, 2(1), 22-38.

Trujillo, G., \& Tanner, K. D. (2014). Considering the role of affect in learning: Monitoring students' selfefficacy, sense of belonging, and science identity. CBE Life Sciences Education, 13(1), 6-15. https:// doi.org/10.1187/cbe.13-12-0241. 
Turnbull, S. M., O’Neale, D. R., Vanholsbeeck, F., Irving, S. E., \& Lumley, T. (2017). A leaky pipe dream? A study of gender differences in undergraduate physics. arXiv preprint https://arxiv.org/abs/1702. 06249. Accessed 10 December 2019.

UNESCO. (2015). UNESCO science report: towards 2030. UNESCO Publishing.

Publisher's Note Springer Nature remains neutral with regard to jurisdictional claims in published maps and institutional affiliations. 